\title{
Risk Management System in Investment Platform Operator's Work
}

\author{
V. V. Zemskov \\ Federal State Funded Educational Instution of Higher \\ Education «Financial University under the Government of \\ the Russian Federation» \\ Moscow Russia. \\ VVZemskov@fa.ru
}

\author{
E. A. Timofeev \\ Federal State Funded Educational Instution of Higher \\ Education «Financial University under the Government of \\ the Russian Federation» \\ Moscow Russia. \\ timofeev043@mail.ru
}

\begin{abstract}
The article examines some aspects of risk assessment and analysis. These risks are related to the introduction of mandatory regulatory requirements for investing and attracting investments using investment platforms. It is connected with that the country's economy has a disproportion of funding sources between sectors of the economy, levels of state and corporate governance [2, p.64]. The effective system is focused on ensuring the competitiveness of the national economy of the state and society. The decline in investment attractiveness caused by the instability of the Russian financial system hinders the development of the national economy.
\end{abstract}

Keywords: risks, risk analysis and assessment, investment attractiveness, operators of investment platforms, competitiveness of the economy

\section{INTRODUCTION}

Modern challenges and threats exist in the country's economy. They are hinder the pace of development of the country and its competitiveness very strongly that made them as negative factors [3, p. 10]. As we know, investments are classified as limited resources [4, p. 24]. This is expressed in the fact that potential investors in the process of investing free money evaluate not only the objects of investment, but also the geographical location, the availability of mineral resources, the availability of logistics. In other words investors evaluate the presence of a developed infrastructure of investment attractiveness [5, p. 71]. Very diverse approaches to determining the essence of the concept of "investment attractiveness" exist. The assessment of external and internal environment factors is an integral aspect of each approach [6, p. 38].

The priorities of the investment attractiveness infrastructure include the formation of investment platform operators (here and further referred to as operators) at all levels of corporate governance. The aim of this is to achieve advance the development of economic sectors, free access to sources of financing for various management entities, as well as providing both methodological and practical assistance in the country's financial market [7, p.751].

It should be noted that methodological assistance rendered by the operators of investment platforms would be to design and define a single transparent rules. These rules should be maintained by subjects of management of investment decisions through the application of a risk-based approach. The essence of the risk-based approach is that economic activity and financial prosperity of operators depends on the successful and effective activity of subjects of management in the financial market, obtaining the maximum economic benefits by them on the basis of reducing risky investments. The practical significance of operators is to provide consulting assistance to management entities in selecting investment objects, diversifying these objects if there are signs of a decrease in the profitability of investment investments.

Thus, in the context of this article, we understand the investment attractiveness of operators as the possibility and ability of these operators to achieve their goals in ensuring the highest profitability of management entities when they use investment objects in the financial market. All this has created the need to develop additional incentives to attract investment from both foreign and domestic investors in order to ensure Russia's financial security.

\section{RISK MANAGEMENT SYSTEM}

For the purposes of this study it is necessary to consider the concept of "operator of investment platforms". It is necessary to analyze the existing uncertainties associated with the operators. First of all, the operator of investment platforms is understood as economic entities whose main type is the organization of the process of attracting free funds in the form of investments in the financial markets of the country. Operators specially register by the mega-regulator [8, p. 9].

Thus, operators carry out their activities in the interests of management entities in order to obtain economic benefits from business activities on the basis of concluded business 
It is necessary to take into account both positive and agreements. The example of such agreements is a contract for the provision of paid services [9, p. 699]. The question is how do operators carry out the process of attracting investment? Investing using the investment platform can be carried out in the following ways:

1. by loans providing;

2. by equity securities purchasing placed using the investment platform with the exception of securities of credit organizations, non-credit financial organizations, as well as structural bonds and securities;

3. by utilitarian digital rights acquisition.

The first two ways of investment attraction do not raise questions for researchers. Therefore, let's consider the essence of investment attraction by purchasing utilitarian digital rights. Article 8 of the Federal law № 259-FZ identifies the following components of utilitarian rights:

1. the right to demand the transfer of a thing;

2. the right to demand the transfer of exclusive rights to the results of intellectual activity and (or) the rights to use the results of intellectual activity;

3. the right to demand the performance of works and (or) the provision of services;

Thus, utilitarian digital rights impose certain obligations on sellers to perform certain actions to fulfill the terms of the concluded contracts. is:

The advantage of using operators in investment activities

1. the absence of intermediaries in the investment of funds;

2. using elements of the digital economy infrastructure, which ensures transparency of the investment process;

3. wide involvement of individuals in the investment process within the country, which increases the volume of funding sources;

4. reducing the time between the date of making investment decisions and the date of receiving economic benefits.

The disadvantages of using the operators in investing activities are as follows:

1. high risk situations for the investor;

2. unfair actions on the part of persons attracting investments;

3. risks of reducing the profitability of investment objects.

The following conclusion can be drawn from the above. The uniqueness of investment platform operators lies in the fact that this investment tool with the use of information technologies and technical means allows you to quickly get money used for profit or other useful effect [10, p.88]. negative aspects of the investment process when using investment platform operators to obtain economic benefits As noted above, investing using the investment platform is highrisk and can lead to the loss of investment in full or in part of them. In this regard, operators are required to inform investors in writing about the presence of risks. They are aware of the entire investment process. They should be aware of the fact that uncertainty, randomness, danger and risk are an integral part of any management process $[11$, p. 6]. In this regard, it is necessary to create a risk management system in the activities of investment platform operators in order to minimize the risks of financial losses of investors.

Operators of investment platforms bear certain risks when participating in investment relationships. In view of this there is a need to assess and rank threats of the investment process. Evaluation and ranking is a systematization that allows you to effectively manage business processes in accordance with threats $[12$, p. 31]. Threats are evaluated based on the results of the risk assessment when the threat is implemented. The risk of threat implementation is determined by the following expression (1):

$$
R=P * L(2),
$$

$\mathrm{P}$ - probability of threat risk realization; for the duration of the commission.

The description is a preliminary stage of direct assessment of the risk of threat implementation. The risks are classified by the areas of activity of persons attracting investments. This helps to conduct further analysis. It is taking into account the consequences and probability of each of the risks. An appropriate risk description format makes it possible to prioritize and highlight those risks that require detailed study [13, p. 31]

The probability and consequences are evaluated on a tenpoint scale. There is a different interval breakdown. The probability scale looks like this:

- minor probability less than $10 \%$;

- small probability $11-20 \%$;

- average probability $21-45 \%$;

- high probability $45-75 \%$;

- $\quad$ significant probability above $75 \%$.

A split into 5 intervals is applied for consequences, including equal intervals with an interval of 2 .

- Insignificant interval 0-2;

- Small interval 2,1-4;

- Average interval 4.1-6;

- Large interval 6.1-8;

- Significant interval 8.1-10.
L- consequences that are equal to the product of damage 
investments using investment platforms. The operator of the investment platform needs to create a risk management system that is integrated into the overall management system. This approach gives the opportunity both to protect the interests of individuals and legal entities and their own interests.

\section{References}

[1] "On attracting investments using investment platforms and on amendments to certain legislative acts of the Russian Federation", Federal law, no. 259-FZ, 02.08.2019, ConsultantPlus legal Reference system [Electronic resource]. Available at: http://www.consultant.ru/ (Accessed: 20.12.2019).

[2] D. Degtyarev, I. Vasilyuk and V. Baum, "Parameters of multi-vector foreign policy of CIS countries: applied analysis", World economy and international relations, no. 1, pp. 63-75, 2018.

[3] V.A. Tsvetkov, M.N. Dudin, and N.V.Lyasnikov, “Analytical approaches and methods of assessing the economic security of the region", Economics of the region, no. 1, pp. 1-12, 2019

As you can see from the table 1, all threats from individuals who attract investments for investors who invest using investment platforms are implemented with an average or even high probability. It is an unfavorable indicator. A small analysis of the probabilities for threats from individuals who attract investments through investment platform operators is explained by the correlation between the implementation factors. Many of them are aggravated scenarios for the same factors. It is possible to take into account the influence of individual threat factors. Analytical threat assessment is used for it [14, p. 37].

It is also usefully for operators of investment platforms to use the risk of express analysis from SPARK [15]. The operator of the investment platform checks the persons who attract investments through this verification service at the preliminary stage of concluding an agreement on investment assistance services. This allows you to evaluate potential threats through the following tools:

- The index of due diligence - a score that shows the probability that a company is a " one-day firm»;

- Financial risk indicator which allows to assess of the probability of insolvency of the company;

- The payment discipline index which is an indicator that takes into account the company's timely payment of invoices at intervals.

\section{CONCLUSION}

It should be noted that the operators of investment platforms are a new subject of the Russian financial market. Investing through investment platform operators is concerning certain risks. The investor must analyze the investment offer before entering into an agreement with a person who attracts
[4] K.P. Onegova, "Management of investment attractiveness of the Corporation", International student scientific Bulletin, no. 2, pp. 23-30, 2016.

[5] V.V. Zemskov and M.A. Rotar, "Influence of financial regulation on investment attractiveness of the Russian Federation", Financial life, no. 2, pp. 69-73, 2019.

[6] A.D. Trushnikova, "Investment attractiveness of the Corporation and approaches to its assessment", Scientific notes of young researchers, no. 5, pp. 36-46, 2017

[7] I.V. Bulava, "Criteria for assessing the investment activity of enterprises", Economics and entrepreneurship, no. 4, pp. 749-755, 2018.

[8] L.A. Novoselova, T.M. Medvedeva, and A.N. Arefyev, "The law on crowdfunding - the first step in creating an infrastructure for the circulation of digital rights", Economy and law, no. 11, pp. 3-16, 2019.

[9] A.V. Ivashchenko and S.A. Goryacheva, "Building software infrastructure in the service sector in the digital economy", Software products and systems, no. 4, pp. 692-696, 2018.

[10] E.V. Chaikina, U.V. Dremova, and V.Y. Chaikin, "Crowdfunding as an alternative to Bank loans", Financial studies, no. 2, pp. 79-91, 2019.

[11] V.I. Avdiyskiy, "Risk Management in the activities of economic entities", Economics, Tallage, The right, no. 4, pp. 4-12, 2013.

[12] G.M. Gambarov, M.U. Musaeva, and A.S. Krupkina, "Risk Indicator of the Russian financial market", Money and credit, no. 6, pp. 29-38, 2017.

[13] N.N. Ilysheva and E.V. Karanina, "Methodological aspects of formation, evaluation and improvement of the system of strategic analysis and management of business risks of the enterprise", Economic analysis: Theory and practice, no. 11, pp. 23-30, 2014.

[14] P.M. Lanskov and E.A. Zenkovich, "Integrated system of internal control and risk management and internal audit in non-credit financial organizations", Money and credit, no. 2 pp. 34-46, 2017.

[15] Information portal of references on Russian and foreign companies, SPARK [Electronic resource]. Available at: http://www.sparkinterfax.ru (Accessed: 20.12.2019). 